\title{
Desfazendo imagens, construindo identidades: decolonizando os processos formativos de educadorxs'
}

\author{
Undoing images, building identities: decolonizing the educational \\ processes
}

\section{Deshaciendo imágenes, constriendo identidades: decolonizando los procesos formativos de educadorxs}

\begin{abstract}
Elison Antonio Paim²
Universidade Federal de Santa Catarina, Departamento de Metodologia de Ensino (MEN) do Centro de Educação, Professor Adjunto
\end{abstract}

\section{Patrícia Magalhães Pinheiro ${ }^{3}$}

Universidade Federal de Santa Catarina, Integrante dos Grupos de Pesquisa Patrimônio, Memória e Educação (PAMEDUC) e Educação e Patrimônio Cultural: entretecendo memórias e histórias da/na ilha de Santa Catarina

\section{Josiane Beloni de Paula ${ }^{4}$}

Universidade Federal de Santa Catarina, Integrante do Grupo de Pesquisa Patrimônio, Memória e Educação (PAMEDUC)

Resumo: Este trabalho dialoga com memórias e experiências de educadorxs que desenvolvem práticas de resistência em sala de aula no que tange à valoração da presença negra e indígena na sociedade brasileira. Essas práticas pretendem criar caminhos e brechas para a reversão de uma ordem opressora, desenraizando, assim, preconceitos impregnados no imaginário social moderno/colonial/ colonialista. Dialogaremos com autorxs decoloniais evidenciando a importância da escola como agente de luta contra a opressão e de valorização de múltiplos saberes e de formas outras de ser e estar no mundo, decolonizando pensares, saberes e práticas. Essas práticas educativas se fazem presentes na pesquisa por meio da construção de narrativas dxs professorxs tidas como fontes orais.

Palavras-chaves: Decolonizar. Práticas de resistência. Relações étnico-raciais.

Utilizamos o x na tentativa de forjar uma escrita não binária. Nossa escrita vai ao encontro do posicionamento da autora decolonial Catherine Walsh em seu texto El uso de la " $x$ " es una opción - de hecho lingüísticamente insurgente $y$ desobediente - para contrarrestar el género binário, em tradução livre 0 uso do " $x$ " é uma opção - linguisticamente insurgente e desobediente - para contrabalançar o gênero binário.

2 Doutor em Educação pela Universidade Estadual de Campinas; Mestre em História pela Pontifícia Universidade Católica de São Paulo; https://orcid.org/0000-0002-7509-5572; http://lattes.cnpq.br/8695520812750828.

3 Mestre em Educação, em Ciências e Matemática pela Universidade Federal de Goiás; Doutoranda no Programa de PósGraduação em Educação na Universidade Federal de Santa Catarina; https://orcid.org/0000-0002-7826-2399; http://lattes. cnpq.br/7553639743042884.

4 Mestre em Educação pela Universidade Federal de Pelotas; Doutoranda no Programa de Pós-Graduação em Educação na Universidade Federal de Santa Catarina; https://orcid.org/0000-0003-3946-3048; http://lattes.cnpq.br/3984650204087167. 
Abstract: This work interacts with the memories and experiences of educators who develop resistance practices in the classroom regarding the evaluation of the black and indigenous presence in brazilian society. These practices aim to create paths and gaps for the reversal of an oppressive order, thereby uprooting impregnated prejudices in the modern/colonia//colonialist social imaginary. We will dialogue with decolonial authors showing the importance of the school as an agent of struggle against oppression and of valuing multiple knowledges and other forms of being and being in the world, decolonizing thoughts, knowledge and practices. These educational practices are present in the research through the construction of narratives of the professors as oral sources.

Keywords: Decolonization. Endurance practices. Ethnic-racial relations.

Resumen: Este trabajo dialoga con memorias y experiencias de educadorxs que desarrollan prácticas de resistencia en el aula en lo que se refiere a la valoración de la presencia negra e indígena en la sociedad brasileña. Esas prácticas pretenden crear caminos y brechas para la reversión de una orden opresora, desenraizando así preconceptos impregnados en el imaginario social moderno/colonial colonialista. Dialogaremos con autorxs decoloniales evidenciando la importancia de la escuela como agente de lucha contra la opresión y de valorización de múltiples saberes y de otras formas de ser y estar en el mundo, decolonizando pensamientos, saberes y prácticas. Estas prácticas educativas se hacen presentes en la investigación por medio de la construcción de narrativas de lxs profesorxs que se toman como fuentes orales.

Palabras clave: Decolonizar. Prácticas de resistencia. Relaciones étnico-raciales.

Recebido em 25 de abril de 2018 Aceito em 10 de outubro de 2018 Publicado em 22 de fevereiro de 2019

\section{INTRODUÇÃO}

"Temos o direito de ser iguais quando a diferença nos inferioriza; temos o direito a ser diferentes quando a igualdade nos descaracteriza."

(SANTOS, 2003).

Este artigo aborda ações positivas na luta para a atenuação do racismo, essa doença social (FANON, 2008) que assola, estruturalmente, a sociedade brasileira, trazendo exemplos de práticas de resistências ${ }^{5}$ realizadas dentro dos espaços educativos escolares, 
as quais, além de debater o racismo, constroem estratégias que visam a seu enfraquecimento. São educadorxs engajadxs na luta por igualdade dos direitos de indígenas e negrxs, xs quais, constituem uma chamada "minoria", que são minorias em direitos, mas maioria numérica em relação ao total da população brasileira. Essxs educadorxs realizam em suas salas de aula práticas de valoração e presença dxs indígenas e negrxs no Brasil, possibilitando axs educandxs verem caminhos entre as brechas, analisar os rastros, para se posicionarem contra a opressão histórica, colonial, colonialista e econômica a que esses segmentos da população brasileira foram/são submetidos ao longo de séculos, uma educação a contrapelo (KRAMER, 2002; BENJAMIN, 2012) e decolonial. Pontuamos que essas práticas de resistência ocorrem diante dos processos de opressão secular, afinal, onde há opressão também teremos resistência, em relação dialética.

Nessa caminhada, nesse viver resistindo, os movimentos sociais foram galgando e conseguindo avanços jurídicos, como importantes marcos legais, a saber: a Lei n. 10.639/20036 e a Lei n. 11.645/2008, dispositivos legais que preveem o ensino da história, cultura, processos de luta, valorização da participação na construção do País, com ênfase nas áreas sociais, econômicas e políticas tanto dxs africanxs e dxs afro-brasileirxs quanto dxs indígenas em todas as etapas da Educação Básica, ou seja, tanto no Ensino Fundamental quanto no Ensino Médio, nas instituições públicas e privadas. Afirmamos que tanto a Lei n. 10.639 quanto a $\mathrm{n}$. 11.645 são mecanismos que corroboram o estímulo, a incitação e a consequente efetivação e concretização de práticas de resistência.

Essas práticas de resistência se fazem presentes na pesquisa por meio da construção de narrativas dxs professorxs tidas como fontes orais. Em movimentos de rememoração (BENJAMIN, 2012; GALZERANI, 2008) xs educadorxs mobilizam suas memórias e experiências, estando estas prenhes de significados, de conhecimentos, de sensibilidades. Compreendemos aqui a rememoração como atividade artesanal produtora de conhecimento. Nesse sentido:

67). A resistência freiriana tem a ver com a possibilidade de mudar o mundo, de não se acomodar, não fraquejar, intervir. A resistência é a prática de rever os conceitos da visão dominante.

6 A Lei n. 10.639, sancionada em 9 de janeiro de 2003, torna obrigatório nos estabelecimentos de Ensino Fundamental e Médio, oficiais e particulares, o ensino sobre História e Cultura Afro-Brasileiras, contemplando o estudo da História da África e dos Africanos, a luta dxs negrxs no Brasil, a cultura negra brasileira e x negrx na formação da sociedade nacional, valorizando a participação do povo negro nas áreas social, econômica e política pertinentes à História do Brasil.

7 Lei n. 11.645, sancionada em 10 de março de 2008. Nos estabelecimentos de Ensino Fundamental e de Ensino Médio, públicos e privados, torna-se obrigatório o estudo da história e cultura afro-brasileira e indigena. 0 conteúdo programático inclui diversos aspectos da história e da cultura que caracterizam a formação da população brasileira, a partir desses dois grupos étnicos, como o estudo da história da África e dos africanos, a luta dos negros e dos povos indigenas no Brasil, a cultura negra e indigena brasileira e x negrx e x índix na formação da sociedade nacional, resgatando as suas contribuições nas áreas social, econômica e política, pertinentes à história do Brasil. Esses conteúdos referentes à história e cultura afrobrasileira e dos povos indigenas brasileiros devem ser ministrados no âmbito de todo o currículo escolar, em especial nas áreas de educação artística e de literatura e história brasileiras. 
[...] rememorar é um ato político, com potencialidades de produzir um "despertar" dos sonhos, das fantasmagorias, para a construção das utopias. Rememorar significa trazer o passado vivido como opção de questionamento das relações e sensibilidades sociais, existentes também no presente, uma busca atenciosa relativa aos rumos a serem construídos no futuro. (GALZERANI, 2008, p. 21).

A rememoração do passado no tempo presente, projetando um futuro, extrapola a individualidade de quem narra, trazendo-nos também indícios do tempo histórico no qual $x$ narradorx está inseridx. Assim, essa opção metodológica de se trabalhar com a história oral, com a arte artesanal de construir narrativas por meio da produção benjaminiana da rememoração, permite-nos realizar a produção de conhecimento histórico. Pontuamos, ainda, que essas narrativas foram construídas por meio de entrevistas que foram gravadas, transcritas e transformadas em miniaturas de significado, em centelhas de sentidos, em mônadas. Essas mônadas têm o poder de tornar as narrativas mais do que comunicáveis, tornam-nas experienciáveis.

Nesse sentido, as narrativas originais foram recortadas e remontadas construindo mônadas $^{8}$ a partir da concepção do filósofo alemão Walter Benjamin (2007, p. 69), na qual "A ideia de mônada, isto significa, em suma, que cada ideia contém a imagem do mundo. A representação da ideia impõe como tarefa, portanto, nada menos que a descrição abreviada do mundo." A forma de apresentar as narrativas procura romper com a linearidade, pois são dispostas de forma que o leitor poderá acessá-las de forma independente e construir suas versões sobre as múltiplas formas de fazer resistência ao racismo e à discriminação em salas de aula.

As mônadas foram construídas enquanto fios de memórias e experiências trançados, entrelaçados, entrecruzados por elementos próprios das subjetividades e identidades $\mathrm{dxs}$ professorxs narradorxs.

\section{DESENUOLUIMENTO}

$\mathrm{Na}$ perspectiva da decolonialidade, refletindo acerca da transformação da sociedade, não mais querendo trocar o sistema, como viemos fazendo ao longo da história, em que sempre temos $x$ colonizadorx e $x$ colonizad $x, x$ que possui as formas de produção

0 conceito poderá ser ampliado a partir de França (2015) e Galzerani (2013a, 2013b). 
e $x$ que tem sua força de trabalho explorada em processos de escravização e/ou venda, para formas de governo na tentativa de inverter essa lógica, $x$ oprimidx e x opressorx. Essa nova epistemologia rompe com visões dualísticas, binárias e antagônicas por excelência, buscando a compreensão da complexidade e das diversas formas de poder, ser e saber. Entendendo a colonialidade não como o período histórico do colonialismo, mas como uma maneira determinada de viver.

0 sociólogo peruano Aníbal Quijano (2000) afirma que a colonialidade se organiza com base na tríade: colonialidade do poder, colonialidade do saber e colonialidade do ser, sendo essa estrutura de dominação exercida em várias manifestações sociais.

A colonialidade do poder se ancora em um complexo sistema de classificação social que tem seu embasamento classificatório em uma hierarquia racial e sexual e sua prática perversa na distribuição de identidades sociais tidas como superiores e inferiores (MALDONADO-TORRES, 2007; PAIM, 2016). De acordo com Quijano (2000) e Maldonado-Torres (2007), a colonialidade do poder se constitui um elemento de conexão entre o racismo, a exploração capitalista, o controle do sexo e o monopólio do saber.

A colonialidade do ser se manifesta na linguagem e na experiência vivida $d x s$ sujeitxs por meio dos processos de inferiorização, desumanização, subalternização $d x$ outrx e na promoção do sufocamento de experiências e formas de vida outra. Segundo o psiquiatra, filósofo e ensaísta marxista francês da Martinica Frantz Fanon (2008) e a intelectual militante Catherine Walsh (2008), a colonialidade do ser promove a "não existência" dxs sujeitxs, xs julgando sempre como não modernxs, não civilizadxs, bárbarxs em contraposição à construção da ideia relacional razão-racionalidade e humanidade. Dessa forma, a colonialidade do ser funda a construção de hierarquias sociais, classificações, normatizações, categorizações que enquadram povos como superiores e inferiores.

Já a colonialidade do saber se manifesta, notadamente, nos mais distintos níveis de ensino, em que há a valorização do conhecimento científico como ponto zero, ${ }^{9}$ cartesiano, moderno, racional e eurocêntrico em detrimento de demais conhecimentos e epistemologias.

Maldonado-Torres (2007, p. 377 apud PAM, 2016, p. 147) cunha o conceito de racismo epistêmico e afirma que esse tipo de racismo hierarquiza grupos como não humanos e, portanto, incapazes de construir epistemologias, conhecimentos, formas de vida "para além das justificações biológicas de racismo, outras justificações baseadas em diferenças

9 De acordo com filósofo colombiano Castro-Gómez (2005, p. 14), em seu livro La Hybris del Punto Cero: ciência, raza e ilustración em la Nueva Granada (1750-1816), o chamado "ponto zero" é um ponto de partida de observação, supostamente neutro, absoluto e universal, no qual a linguagem científica foi construída "como a mais perfeita de todas as linguagens humanas", tratando como obstáculos epistemológicos todos os saberes outros, forjando, assim, a mais pura estrutura universal da razão. 
de cultura ou maneira de estar, é possivel encontrar [...] uma justificação ontológica e epistemológica mais subtil." Podemos nos ancorar no que Quijano (2000, p. 342) nos traz para a reflexão:

\begin{abstract}
A colonialidade é um dos elementos constitutivos e específicos do padrão mundial de poder capitalista. Se funda na imposição de uma classificação racial/étnica da população do mundo como pedra angular do dito padrão de poder e opera em cada um dos planos, âmbitos e dimensões materiais e subjetivas, da existência social cotidiana e da escala social. Origina-se e mundializa-se a partir da América.
\end{abstract}

Mas essa visão mais ampla de mundo, respeitando saberes e formas diferentes de viver, lutar para retirar, sim, a colonização do ser (sentir), do saber, do poder, mas não para colocar novos dominantes, é um viver de rupturas com a hierarquização e a padronização do mundo, olhar o mundo nas suas diferentes formas de estar nele, trabalhar com as diferenças.

Fugindo de um único modo de vida global, eurocentrado, definido por poucxs, para todxs, o qual define as práticas sociais, visualizando e experienciando maneiras não reconhecidas pelo sistema vigente, mas que possibilitam viver de forma autêntica e plena de suas oportunidades.

Além da tríade poder, saber e ser, a colonialidade também ocorre com relação ao imaginário e à natureza. No pensamento de Quijano (2005):

\footnotetext{
Assim a colonialidade do poder reprime os modos de produção de conhecimento, os saberes, o mundo simbólico, as imagens do colonizado e impõe novos [...] já a colonialidade do saber, entendida como a repressão de outras formas de produção de conhecimento não-européias, que nega o legado intelectual e histórico de povos indigenas e africanos, reduzindoos, por sua vez, à categoria de primitivos e irracionais, pois pertencem a "outra raça".
}

Assim, a discussão da decolonialidade dxs negrxs e indígenas no Brasil hoje se torna indispensável para construirmos uma sociedade pautada no respeito e valorização da diferença, na interculturalidade e nas múltiplas formas de vivenciá-la. Pois a interculturalidade é uma experiência existencial. Como nos ressalta Walsh (2008), a decolonialidade implica:

\footnotetext{
[...] partir da desumanização e considerar as lutas dos povos historicamente subalternizados pela existência, para a construção de outros modos de viver, de poder e de saber. Portanto, decolonialidade é visibilizar as lutas contra a colonialidade a partir das pessoas, das suas práticas sociais, epistêmicas e políticas.
} 
Dessa forma, encontramos nas palavras de Walsh a legitimidade para seguir na construção desse pensamento, no que tange a estudos com sujeitxs que são colonizadxs ao longo da história, quando esta nos traz o conceito de interculturalidade.

\begin{abstract}
A interculturalidade crítica [...] é uma construção de e a partir das pessoas que sofreram uma experiência histórica de submissão e subalternização. Uma proposta e um projeto político que também poderia expandir-se e abarcar uma aliança com pessoas que também buscam construir alternativas à globalização neoliberal e à racionalidade ocidental, e que lutam tanto pela transformação social como pela criação de condições de poder, saber e ser muito diferentes. Pensada desta maneira, a interculturalidade crítica não é um processo ou projeto étnico, nem um projeto da diferença em si. [...] é um projeto de existência, de vida. (WALSH, 2007, p. 8).
\end{abstract}

Walsh (2007) nos coloca um processo em construção de uma pedagogia decolonial, baseada na práxis propositiva, não só denunciativa e para inspirá-la traz os referenciais de Paulo Freire e Frantz Fanon, referentes à consciência dx oprimidx e à necessidade de retomada da humanização dos povos subalternizados.

Tendo em vista que a escola está inserida em um sistema excludente, muitas vezes reforçando-o, buscamos conceitos freirianos denúncia/anúncio para discutir a temática racial, nesse sistema ainda colonial. A denúncia do racismo na sociedade e o anúncio de formas de combatê-lo por meio de práticas emancipatórias e de resistência utilizadas por professorxs são estratégias para a transformação da realidade vigente (CRUZ; PROENÇA; OLIVEIRA, 2013).

\footnotetext{
Denúncia de uma realidade desumanizante e anúncio de uma realidade em que os homens possam ser mais. Anúncio e denúncia não são, porém, palavras vazias, mas compromisso histórico [...] A percepção ingênua ou mágica da realidade da qual resultava a postura fatalista cede seu lugar a uma percepção que é capaz de perceber-se. E porque é capaz de perceber-se enquanto percebe a realidade que the parecia em si inexorável, é capaz de objetivá-la. (FREIRE, 1987, p. 42-43).
}

Podemos pensar em superar preconceitos, que aparecem em suas diversas facetas discriminatórias, no imaginário social, por meio do conceito de discriminação que Freire (2000a, p. 39) nos alerta, quando nos diz: "Faz parte do pensar certo a rejeição mais decidida a qualquer forma de discriminação." 
Também na terceira carta do livro Pedagogia da Indignação, Freire nos impulsiona, pois já no início da carta ele coloca o seu pensamento com relação à "L...] posição do pobre, do mendigo, do negro, da mulher, do camponês, do operário, do índio [...]" de violência, de descaso com a vida, o que podemos verificar em vários momentos da nossa vida cotidiana na sociedade atual (CRUZ; PROENÇA; OLIVEIRA, 2013). Sendo naturalizado o ato de colocar fogo em um indigena que dormia em um ponto de ônibus na capital federal ou assassinar um professor indigena em Santa Catarina imaginando que ele roubaria, sendo este $\circ$ descaso total com a vida e com o que chamamos de humanxs, mas que a colonialidade transforma em sub-humanos ou não seres.

Para investirmos contra essa naturalização, a saída é a transformação de atitudes, o trabalho do bem geral, a valoração do humanx, que se dará pela conscientização, que $x$ sujeitx saiba seu papel social, interfira, seja autorx e não somente telespectadorx, tenha seus saberes e fazeres em pé de igualdade com os oficialmente legitimados.

Assim, salientamos práticas de resistências realizadas na escola referentes à valoração da presença negra e indígena no Brasil, para visualizar os esforços de educadorxs na transformação da realidade social brasileira.

Como o caso da professora Ashanti, a qual narra sempre ter presente em suas aulas a discussão da presença negra na sociedade brasileira, por ter consciência da importância vivida em suas experiências na escola como educanda e agora como educadora negra:

\footnotetext{
Trago, assim, óh, por eu ser diretora da escola, e eu já cheguei com uma resistência enorme. Eu tive que fazer uma, uma, denúncia na delegacia em função de preconceito. A escola parou pra olhar, tipo assim, aí elas não querem ela aqui, né. Só que as pessoas não conseguiam separar, uma coisa é a discriminação, e que eu posso ir até uma delegacia, porque eu fui alvo de racismo, a outra coisa é tu aceitar ou não, mas, assim, óh, fui eleita, votaram. Então, eu entrar no portão, e as pessoas questionarem, assim, óh. 0 que que essa negra burra tá fazendo aie Como é que botam uma negra de diretora da escola?" Aí alguns colegas vão dizer assim, claro isso é porque tem, aqui que é muita criança branca, né, são poucas crianças negras, e ai pra comunidade fica difíil que tu estejas coordenando a escola, só um pouquinho. Então não posso sair na rua, porque lá tem um monte de pessoas brancas, e eu sou a única negra? Isso autoriza as pessoas a me desrespeitar? Não! E as pessoas querendo me convencer de que eu não fosse até uma delegacia, que isso poderia ser pior pra mim. Então, assim, óh, são coisas que começou a discussão na escola, muito mais em função, porque antes quando eu tava na sala de aula, professora, eu trabalhava estas questões na minha sala de aula. Quando eu me torno diretora da escola e que eu sou vítima dessa discriminação no portão da escola a
} 
público, isso vira uma questão de escola, com todos. Assim, óh, vamos ter que parar, vamos ter que discutir, porque não tem jeito. E agora o que que acontece, quando tem qualquer situação, "diretora tão discriminando fulano de tal". E o que que tu estás fazendo na sala de aula? Porque não é eu ir lá conversar com os alunos e dizer que isso é crime, tudo mais. Onde é que essas pessoas passam no teu planejamento todos os dias. $E$ ai me incomoda muito, porque que eu lembro das falas iniciais dos colegas, assim tipo. Aí tem que entender que pra eles é dificil mesmo; numa escola onde $90 \%$ das crianças são brancas, com pouquinhos negros, aí daqui a pouco a diretora é negra e aí o que que aconteceu, a coor... A orientadora da escola não queria ficar com uma diretora negra. Ela pediu pra sair, e a orientadora que veio foi uma negra. Então, assim, óh, virou tipo a escola não é mais a mesma, a escola não é mais tão boa como era antigamente. Por quê? Porque tá na liderança duas figuras negras. Então isso, assim, óh, pra mim é muito, ah, passou o preconceito. Passou gurias!? Não é uma doença que dá e passa, né? Não passou, tá ali. Nós estávamos há pouco tempo, no comecinho de 2016, com toda essa discussão, com toda essa problemática, e vocês achando que a comunidade tinha razão, que estar no comando uma mulher negra, isso desqualificava as pessoas, desrespeitavam, como um senhor disse "Me sinto desrespeitado" Como assim? Sabe? Então [...] (Ashanti) (informação verbal)."

Essa narrativa não só nos mostra a denúncia de uma sociedade, mas a instituição escola racista e uma professora que traz para a discussão com toda a comunidade escolar o anúncio de práticas de resistências a essas investidas, por meio do desvelamento, mostrando o problema para que se reflita sobre possiveis soluções.

Outro pensamento de Freire que compartilhamos é que não há neutralidade, sempre temos uma posição: ou estamos do lado do opressor ou do oprimido, toda ação é política. Então a questão da discriminação e de sua erradicação é uma posição que temos que tomar, é uma atitude que precisamos exercitar; se lutamos por uma sociedade justa, se nossa opção é libertadora, devemos trabalhar pela equidade, pela convivência com o diferente e não por sua negação.

\footnotetext{
Para que haja uma real transformação, uma descolonização (FREIRE, 2000b) das mentes é preciso a práxis e começar por nós, cada um deixando para suas gerações experiências de amorosidade, de respeito a todos os seres da natureza. É sem dúvida uma construção coletiva, é por meio da desnaturalização dos preconceitos, dos desrespeitos e partir para uma construção $d x s$ sujeitxs que buscam a sua conscientização, descobrem seu inacabamento e procuram "ser mais", ou seja, saem de uma ideia superficial, exercitam uma capacidade estritamente humana e que nos diferencia do restante da natureza: a reflexão. (CRUZ; PROENÇA; OLIVEIRA, 2013).
}

" Entrevista realizada em 19 de julho de 2017, em Pelotas-RS, pela pesquisadora Josiane Beloni de Paula, para composição de sua tese de doutorado. 
Assim, as práticas de resistências, as quais ocorrem nas salas de aulas, são contribuições para a construção de um projeto de sociedade para todxs e não como ainda temos hoje, legalmente sujeitxs com os mesmos direitos, e nas experiências diárias situações que declaram a impossibilidade de exercê-los.

Por exemplo, quando xs professorxs/educadorxs conseguem ver $\mathrm{x}$ educandx como um ser integral, com direitos e deveres, dificuldades e progressos, a professora Ashanti (informação verbal) nos auxilia:

\footnotetext{
[...] me preocupa quando ele tá fedendo, "Ah, não aguento o fedor do fulano", mas eu não quero saber que contexto aquela criatura vive, qual é a condição dele, o que que enquanto escola a gente pode fazer, discutir. Não é um assistencialismo, "Vamos dar um banho nele e deu". Não! Como é que a gente discute com o nosso grupo de alunos essa situação do fulano, porque não é só dele, é nossa, na verdade. Porque quando, assim, o fulano tem quinze espiners e o colega dele tá chorando porque ele não tem nenhum, como é que tu faz pra ele perceber que ele tá numa situação de "vantagem" em relação àquele outro e que aquele tá sendo impedido de ter algo que deveria ser direito dele também, de ter uma cama quente, de ter um leite, de ter um brinquedinho [...]
}

Nesse texto também podemos nos remeter novamente à discussão do anúncio e da denúncia, pois a todo momento na obra de Freire ele denuncia as barbáries, como na terceira carta, ele nos mostra o acontecimento horroroso ocorrido, mas nos propõe não sermos meros expectadores da vida e, sim, anuncia que, com trabalho árduo e de conscientização, podemos construir uma nova sociedade. Freire (1987, p. 44) nos propõe pensarmos que "não há denúncia verdadeira sem compromisso de transformação, nem este sem ação."

Assim, a denúncia é do racismo na escola, consequentemente na sociedade. Essa é uma situação limite, enquanto o anúncio são práticas escolares e cotidianas que possibilitem a transformação do problema que é o inédito viável.

Logo, a denúncia de uma sociedade racista, que é a situação-limite, e o anúncio de práticas de resistências, que pode ser interpretado como o inédito-viável, quando ocorrem de formas contínuas, nos aproximam do que Freire assegura.

0 inédito-viável não é, pois, uma simples junção de letras ou uma expressão idiomática sem sentido. É uma palavra na acepção freiriana mais rigorosa. Uma palavra-ação, portanto, práxis, pois não há palavra verdadeira que não seja práxis, daí, quer dizer que a palavra verdadeira seja transformadora 
do mundo (1975, p. 91). Uma palavra epistemologicamente empregada por Freire para expressar, como enorme carga afetiva, cognitiva, política, epistemológica, ética e ontológica, os projetos e os atos das possibilidades humanas. (STRECK; REDIN; ZITKOSKI, 2010, p. 224).

Com o pensamento crítico $x$ sujeitx rompe com a situação de opressão, vai havendo a conscientização, a tomada de consciência diante de sua realidade e do seu direito de ser mais, também do seu dever de lutar para que de fato isso ocorra e, sendo assim, tornar-se sujeitx, oportunizando a criação de situações libertadoras, o que seria o anúncio do "inédito viável", a resistência, a transformação da situação.

Encontramos nas práticas de educadorxs as resistências contra o preconceito étnico-racial. Trazendo novamente o que diz Paulo Freire, resistência no sentido de oposto à desistência. Resistência pressupõe briga entre desiguais, tem a ver com possibilidade de mudar o mundo, de não se acomodar, não fraquejar, intervir. É estar certo que é possível viver diferente. Assim, a professora Ashanti se mantém na gestão, além de toda uma militância para o trabalho contra a opressão, o racismo e a discriminação ser realizado na escola.

E é importante destacar que a desigualdade não se restringe apenas às questões étnico-raciais; estão presentes, também, nas questões de gênero, sexistas, classistas, linguísticas, regionais, religiosas, na produção/valorização do conhecimento. Dessa forma, temos hierarquias sociais que atuam de maneira relacional e interseccional. De acordo com a advogada, ativista e professora estadunidense Crenshaw (2002), a discriminação opera em diversas identidades sociais, como: "classe, casta, raça, cor, etnia, religião, origem nacional e orientação sexual, são 'diferenças que fazem diferenças' na forma como vários grupos de mulheres vivenciam a discriminação."

Crenshaw (2002, p. 177) nos traz a ideia de interseccionalidade:

\begin{abstract}
A associação de sistemas múltiplos de subordinação tem sido descrita de vários modos: discriminação composta, cargas múltiplas, ou como dupla ou tripla discriminação. A interseccionalidade. É uma conceituação do problema que busca capturar as consequências estruturais e dinâmicas da interação entre dois ou mais eixos da subordinação. Ela trata especificamente da forma pela qual o racismo, o patriarcalismo, a opressão de classe e outros sistemas discriminatórios criam desigualdades básicas que estruturam as posições relativas de mulheres, raças, etnias, classes e outras. Além disso, a interseccionalidade trata da forma como ações e políticas específicas geram opressões que fluem ao longo de tais eixos, constituindo aspectos dinâmicos ou ativos do desempoderamento.
\end{abstract}

No Brasil essas hierarquias combinadas entre si estão intimamente ligadas ao processo de formação das nossas diferenças sociais e, consequentemente, dos locais que 
ocupamos na sociedade, dessa forma vividas por nós, nas mais diversas relações, como na escola.

Com o advento do desenvolvimento científico tanto nas ciências naturais quanto nas sociais o conceito de raça se torna cada vez mais questionado em sua eficácia científica. Sobre essa problemática o sociólogo brasileiro Rafael Guerreiro Osório (2008, p. 84) afirma:

Não existe nenhuma pesquisa que comprove que a cor da pele, ou outras características físicas implicariam em certos comportamentos morais ou qualidades essenciais a um determinado povo como se acreditava no final do século XIX. No final da segunda guerra mundial depois do holocausto nazista, houve um esforço muito grande por parte de geneticistas, biólogos, antropólogos e sociólogos no sentido de banir o conceito de raça das ciências. [...] 0 conceito de cultura seria muito mais viável para se pensar as diferenças humanas do que o conceito de raça. 0 mundo social está intimamente ligado a um universo simbólico que lhe dá sentido e significado. Se do ponto de vista da natureza o conceito de raça não se sustenta para discutir nossas diferenças, apesar disso, ele ainda opera na vida social. Os seres humanos se pensam e se classificam enquanto pertencentes às raças.

Como podemos perceber na fala da professora lyokù (informação verbal) ${ }^{12}$ ao narrar uma situação de discriminação por ela vivida:

\begin{abstract}
[...] Eu disse: "sim, sou eu" [...] tem várias fotos da minha infância, da minha adolescência; e eu não fui me transformando, eu continuo a mesma negra que eu sempre fui. E aí ela parou, assim, "Bah, prof., eu achei que tu era afroconveniente" e eu disse "Ah, é? Tu achou? Mas eu não sou" [...] Aí começou a falar que a gente precisa ter a garantia da representatividade, para que as pessoas identifiquem. Eu concordo! Mas o engraçado é que o segurança do shopping, nunca erra. Ele sempre vai atrás de mim... E engraçado que as minhas colegas quando me veem no elevador, e obviamente que eu me emociono com isso, porque [chorol é uma coisa muito ruim de tu passar... Eu tava no elevador com uma cafeteira, dentro da Faced [Faculdade de Educaçãol, já professora, e uma colega entra no elevador, me vê com a cafeteira, e eu digo pra ela assim: "Ah, eu tenho uma caixa lá na sala, que é pra ti", que era uma caixa que uma bolsista minha tinha recolhido, que era pra entregar pra ela, e ela disse: "Para mim? Assim, tá, mas qual é o teu setor?" Quando a gente se refere assim, a gente se refere às terceirizadas e pessoas que são técnicos, e eu disse: "0 meu setor?" E ela: "É". Eu disse: " 0 DE" [Departamento de Educação] "Ah, tá, tu é bolsista de quem?" E eu disse: "Não, eu não sou bolsista." Ela disse: "Ah, tá, é docente?" E eu: "Sim" "Ah, tu fez a seleção?" E eu disse: "Não eu sou efetiva, eu fiz o concurso." "Ah, é, é que a gente não conhece os professores novos." Aí eu digo tá, né, então, como dizer, como lidar direito [chorol. Ela não me conhece, mas o racista
\end{abstract}


reconhece. Então ele tem mais habilidades pra conhecer... E aí essa foi uma situação. Uma outra eu fui na Ulbra [Universidade Luterana do Brasill, fui dá uma palestra na Ulbra. E ai eu cheguei lá, e, veja, com o cabelo liso, né, podia dá uma melhorada, então, na percepção, que dizem, bom vão me ver melhor. Então, tá, cheguei lá na Ulbra, e a mulher olhou assim pra mim e disse assim: "Pra ti é o quêe É FIES? [Fundo de Financiamento Estudantill Pra ti é PROUNI? [Programa Universidade para Todosl, e eu disse: "Não." Deixei ela dize, ai ela disse assim: "Ah, tá, mas, o FIES tu sabe que não tem mais." "Mas eu não vim procurar financiamento, o meu nome deve tá aí na lista da senhora. Eu sou a professora lyoukù, eu sou professora da UFRGS [Universidade Federal do Rio Grande do Sull. Aí ela olhou pra mim, "Ah... Desculpa professora, desculpa. E esses desculpa professora eu já passei por milhares deles. Então essas questões incomodam bastante. Mas eu entendo, eu entendo que a marca da pele escura, ela é bem mais notória, e numa sociedade que hierarquiza, então tu ser negro, mas tu ser negro e pobre ou tu ser negra, tu ser negro, tu ser mulher, mulher negra e pobre ou mulher negra e classe média ou tu ser mulher negra analfabeta ou tu ser mulher negra com a pele escura e analfa... Eu sei que isso, que isso é visivel, assim, mas são muitas situações as quais eu tenho certeza que alguém que de fato é branco não passou. Então é óbvio que isso [choro] é uma característica que não deixa quem é negro esquecer que é negro. Então é impossivel dizer que ela alisou o cabelo e esqueceu que era negra, não é impossivel, isso não acontece, o que acontece é de fato, talvez tu perceber que não adianta disfarçar [.... ${ }^{13}$

Assim, asseguramos que a raça é uma construção social criada e fortalecida pelo sistema moderno/colonial, ou seja, a cor da pele ou a raça de uma pessoa se associa a significados simbólicos de discriminação, dominação e opressão. Compreendemos, então, que no Brasil ser negrx, indígena e brancx implicam diferenças de tratamento, manifestadas desde o acesso a escolaridade, saúde, mercado de trabalho, segurança, moradia (direitos básicos) até critérios estéticos de beleza. Dessa forma, a raça operará como critério de pertencimento/preenchimento de diversas estruturas sociais, inclusive de classe. Ainda segundo Osório (2008): "Nesse sentido, a raça funciona como um mecanismo adscritivo de criação de desvantagens no acesso ao mercado de trabalho e outros setores da vida social" para uns, ao passo que assegura privilégios para outros.

Dialogando com esses autorxs podemos perceber que as interseccionalidade e a questão de raça no Brasil diferenciam xs sujeitxs, além de nos mostrar o racismo vigente, na sociedade e consequentemente na escola.

Xs educadorxs que ousam trabalhar $x$ negrx como sujeitx históricx na sala de aula, mesmo antes da obrigatoriedade da legislação, pois as lutas criam as leis, resistem ao sistema excludente no qual sobrevivemos, onde o importante no capitalismo é o ter e não o ser. Ser cidadão hoje é ter o direito de compra, por isso essas práticas de resistência,

13 Entrevista realizada em 13 de julho de 2017, em Florianópolis, SC, pela pesquisadora Josiane Beloni de Paula, para composição de sua tese de doutorado. 
realizadas por educadorxs comprometidxs, remetem-nos novamente ao educador Paulo Freire, o qual nos orienta que no compromisso do Educador com a sua prática deve haver rigorosidade, comprometimento e afetividade (FREIRE, 1978, p. 7-8).

Nessas práticas emancipatórias, quando $x$ sujeitx problematiza sua realidade, toma consciência de sua situação de opressão, reflete e realiza um movimento de reconstrução de si e de seu contexto, começa a busca por ser mais, que para Freire é uma vocação ontológica (FREIRE, 1987, p. 23). Ou seja, x humanx tem inerente o lutar para sair da opressão, pela humanização, por se construir por saber de seu inacabamento, para poder, então, exercer seus direitos e deveres. A educação popular é um instrumento que contribui para a libertação desse sujeitx. Para Freire, $x$ educadorx comprometido, que colabora para a transformação da sociedade, valoriza e respeita os conhecimentos trazidos pelxs educandxs.

Ainda trabalhando na perspectiva de que as práticas de resistência são uma forma de trazer a presença negra para a escola, buscamos na professora brasileira Eliane Cavalleiro a referência do que apregoa a educação antirracista:

\footnotetext{
No cotidiano escolar, a educação anti-racista visa à erradicação do preconceito, das discriminações e de tratamentos diferenciados. Nela, estereótipos e idéias preconcebidas, estejam onde estiverem (meios de comunicação, material didático e de apoio, corpo discente, docente etc.), precisam ser duramente criticados e banidos. É um caminho que conduz à valorização da igualdade nas relações. $E$, para isso, o olhar crítico é a ferramenta mestra. (CAVALLEIRO, 2001, p. 150).
}

Nesse sentido, vislumbra-se possibilitar aos indivíduos pertencentes ao grupo de atingidxs pelos preconceitos a reconquista de uma identidade positiva, dotada de amor e orgulho próprios. Nela é permanente o combate aos sentimentos de inferioridade e superioridade, visto que a palavra máxima da educação antirracista é a igualdade entre xs humanxs (CAVALLEIRO, 2001).

\section{CONSIDERAÇÕES FINAIS}

Podemos perceber que se instala outro olhar acerca da educação, um enfoque no todo, na escola formada por todxs xs atorxs que a compõem, no qual o preconceito e a discriminação devem ser visualizados e exterminados, via problematização e construção de um pensamento crítico. Esse pensamento nasce na escola e se expande para a sociedade 
em geral quando trabalhadas questões referentes à etnia negra, com reflexões que vão modificando pensares de educadorxs, educandxs e comunidade escolar.

Também podemos citar o antropólogo e professor brasileiro-congolês Kabengele Munanga (2005) a fim de reforçar a importância da mobilização para uma nova prática educacional, já que o autor afirma que embora não hajam leis capazes de erradicar o preconceito e a discriminação racial, já que essas atitudes são provenientes de sistemas culturais, temos na educação a possibilidade de questionamento e desconstrução de mitos de superioridade e inferioridade entre humanos. Ele aponta, ainda, a centralidade dxs educadorxs na luta antirracista e na construção de uma sociedade mais democrática, na qual as individualidades históricas e culturais das populações que formaram a matriz plural do povo brasileiro são recuperadas, reparadas, respeitadas, valorizadas e destacadas.

Com Munanga (2005), podemos verificar a importância de uma mudança individual para uma transformação educacional e, consequentemente, social; x professorx x propulsorx do ideal de uma sociedade justa, propondo reflexões e ações que revoguem, desconstruam e reconstruam as normas apregoadas pelo sistema vigente.

Assim, $x$ professorx, sendo $x$ propulsorx de um ideal de transformação da sociedade, deve proporcionar a construção do pensamento crítico para xs educandxs, incluindo a compreensão da historiografia brasileira e a construção da memória coletiva. É importante salientar que conhecer aspectos da história e cultura da população negra e indígena não deve se restringir apenas axs educandxs negrxs e indígenas, sendo do interesse de todos, principalmente dxs brancxs, afinal, ao receberem uma educação envenenada por preconceitos, todos têm suas estruturas psíquicas afetadas. Para além disso, não há uma memória que seja pertencente somente axs negrxs e indígenas. A memória pertence a todxs, já que a cultura da qual nos alimentamos cotidianamente advém de todos os segmentos étnicos, que, embora em posições assimétricas, contribuíram à formação do nosso País e à riqueza econômica, social e identitária (MUNANGA, 2005).

As africanidades, como coloca Munanga (2005), são histórias que interessam a todxs, acontecimentos que têm o direito de estar nas nossas memórias e estudos na mesma condição dos atualmente aceitos e legitimados; são conhecimentos de todo o nosso povo e devem ser procurados e rememorados.

Todx sujeitx, seja de qual etnia for, deve ter acesso e direito garantido de conhecer as várias histórias contadas pelos mais diversos olhares; principalmente a etnia negra que sempre teve negada sua expressão ou sendo permitida apenas como segunda voz, pouco ou nada ouvida. No entanto, as africanidades brasileiras são oriundas das raízes africanas, são os modos de ser, de viver, de estar, dos negros brasileiros, são as marcas que trazemos 
como brasileiros, independentemente da ascendência étnica, hábitos e costumes cotidianos, como afirma Silva (2005, p. 156):

\begin{abstract}
As africanidades brasileiras vêm sendo elaboradas há quase cinco séculos, na medida em que os africanos escravizados e seus descendentes, ao participar da construção da nação brasileira, vão deixando nos outros grupos étnicos com que convivem suas influências e, ao mesmo tempo, recebem e incorporam as destes. Portanto, estudar as Africanidades Brasileiras significa tomar conhecimento, observar, analisar um jeito peculiar de ver a vida, o mundo, o trabalho, de conviver e de lutar pela dignidade própria, bem como pela de todos descendentes de africanos, mais ainda de todos que a sociedade marginaliza. Significa também conhecer e compreender os trabalhos e criatividade dos africanos e de seus descendentes no Brasil, e de situar tais produções na construção da nação brasileira.
\end{abstract}

São várixs autorxs trabalhando para a construção de outra educação, de outro projeto escolar que seja para todxs. São grupos de trabalho que tratam da temática dx negrx nas mais diversas situações: as questões das cotas, materiais didáticos, mídia, relações sociais, institucionais, étnico-raciais, educação antirracista - e o que mais envolver essxs sujeitxs - a fim de denunciar a opressão e resistir por meio de ações e práticas que possibilitem a efetiva transformação desse panorama.

Essa consolidação levará muito tempo para garantir que muitos descendentes dessa história possam construir suas identidades sem se sentirem em desvantagem ou desiguais perante uma sociedade que marginaliza quem foge ao estabelecido como padrão, como norma. As minorias, hoje assim chamadas, como no caso da etnia negra, são minorias não em números, mas em poder, em representação social, ou melhor, em visibilidade.

Este texto debateu um tema já muito estudado, porém com um diferencial, não vem mais com o único intuito de pontuar o problema, ou seja, de que existe o racismo, o preconceito e a discriminação étnica e racial no Brasil, mas procuramos investir na transformação de um cenário construído ao longo da história e camuflado em uma tentativa de invisibilidade de sua existência.

Vem com a intenção de gerar referências, outros pensares, abordando a visão de educadorxs comprometidxs com a discussão em questão, mas que pode servir para incentivar tantxs outrxs tocadxs, mas ainda sem iniciativas, a iniciarem pela escola com práticas de resistência, as quais dão visibilidade à situação histórica e atual de indígenas e negrxs na sociedade brasileira.

0 que se almeja, enfim, é a atenuação do racismo que existe em nosso País como uma doença severa, o racismo visto como uma doença social, algo que prejudica as relações sociais, distanciando xs sujeitxs. Investindo no contágio da cura, no qual a sociedade, por 
meio de práticas de resistências realizadas por educadorxs na escola, influencia a tomada de consciência dxs sujeitxs a fim de que, com o tempo, a transformação social ocorra de fato.

Dessa forma, contagiando outrxs, a educação torna-se um antídoto para a redução dos danos, ou seja, as práticas de resistência indígena e negra na sala de aula, as cotas raciais em diversos setores da sociedade, uma visão clara da situação vivida atualmente pelxs indígenas e negrxs na sociedade brasileira, levando à reparação e, utopicamente, ao extermínio do mal, da doença - o racismo.

\section{REFERÊNCIAS}

BENJAMIN, W. Experiência e pobreza. Magia e técnica, arte e política. Tradução: Paulo Sérgio Rouanet. São Paulo: Brasiliense, 2012.

BENJAMIN, W. Passagens. Belo Horizonte: Ed. da UFMG/Imprensa Oficial do Estado de São Paulo, 2007.

CASTRO-GÓMEZ, S. La hybris del punto cero: ciencia, raza e ilustración en la Nueva Granada (17501816). Bogotá: Editorial Pontificia Universidad Javeriana, 2005.

CAVALLEIRO, E. (org.). Racismo e Anti-Racismo na Educação: repensando nossa escola. São Paulo: Summus, 2001.

CRENSHAW, K. W. Documento para o encontro de especialistas em aspectos da discriminação racial relativos ao gênero. Estudos Feministas, Florianópolis, v. 10, n. 1, p. 171-188, 2002. Disponível em: https://periodicos.ufsc.br/index.php/ref/article/view/S0104-026X2002000100011. Acesso em: 20 maio 2017.

CRUZ, J. B. da; PROENÇA, K. A. P.; OLIVEIRA, N. A. A denúncia do racismo na nossa sociedade e o anúncio de práticas de resistência que almejam a superação da denúncia. In: COLÓQUIO INTERNACIONAL PAULO FREIRE, 8., 2013, Recife. Anais [...]. Recife, 2013.

FANON, F. Pele negra máscaras brancas. Salvador: EDUFBA, 2008.

FRANÇA, C. S. 0 canto da Odisseia e as narrativas docentes: dois mundos que dialogam na produção de conhecimento histórico-educacional. 2015. 349 f. Tese (Doutorado em Educação) - Universidade Estadual de Campinas, Campinas, 2015.

FREIRE, P. Cartas à Guiné Bissau - Registros de uma experiência em processo. 2. ed. Rio de Janeiro: Paz e Terra, 1978.

FREIRE, P. Pedagogia da Autonomia: Saberes necessários à prática educativa. 15. ed. Rio de Janeiro: Paz e Terra, 2000a. 
FREIRE, P. Pedagogia da Indignação: Cartas pedagógicas e outros escritos. São Paulo: Editora Unesp, $2000 \mathrm{~b}$.

FREIRE, P. Pedagogia do Oprimido. 17. ed. Rio de Janeiro: Paz e Terra, 1987.

GALZERANI, M. C. B. Escola e Conhecimento de História e Geografia: uma disciplina acadêmica e a educação das sensibilidades. Revista Antíteses, Londrina, v. 6, n. 12, p. 126-147, jul./dez. 2013a.

GALZERANI, M. C. B. Imagens que lampejam: contribuições de Walter Benjamin para a produção de conhecimentos históricos. Encuentro de Saberes. Luchas populares, resistências Y educación, Buenos Aires, v. 1, p. 53, 2013b.

GALZERANI, M. C. B. Memória, tempo e história: perspectivas teórico-metodológicas para a pesquisa em ensino de história. Cadernos CEOM, Chapecó: Unochapecó, n. 28, 2008.

GELEDÉS. Instituto da mulher negra. Significados dos nomes próprios africanos. Disponivel em: https:// www.geledes.org.br/significados-dos-nomes-proprios-africanos/. Acesso em: 11 jan. 2018.

GOOGLE TRADUTOR. Disponivel em: https://translate.google.com.br/?hl=pt-BR\&gl=br\&um=1\&ie=UTF-8\&client=tw-ob\#pt/yo/sobrevivente,\%20https://www.geledes.org.br/significados-dos-nomes-proprios-africanos/. Acesso em: 20 jan. 2018.

KRAMER, S. Por Entre as Pedras: arma e sonho na escola. 3. ed. São Paulo: Ática, 2002.

MALDONADO-TORRES, N. Sobre la colonialidad del ser: contribuiciones al derarrollo de um concepto. In: CASTRO-GÓMEZ, S.; GROSFOGUEL, R. El giro decolonial. Reflexiones para uma diversidad epistêmica más Allá del capitslismo global. Colombia: Siglo del Homem Editores, 2007. p. 127-167.

MUNANGA, K. Superando o racismo na escola. 2. ed. Brasilia, DF: MEC/Secad, 2005.

OSÓRIO, R. G. Desigualdade racial e mobilidade social no Brasil: um balanço das teorias. In: THEODORO, M. (org.). As políticas públicas e a desigualdade racial no Brasil: $१ 20$ anos após a abolição. Brasilia, DF: IPEA, 2008. p. 65-96. Disponivel em: http://www.ipea.gov.br/portal/images/stories/Livro_desigualdadesraciais.pdf. Acesso em: 20 set. 2016.

PAIM, E. A. Para além das leis: o ensino de culturas e histórias africanas, afrodescendentes e indígenas como decolonização do ensino de História. In: MOLINA, A. H.; FERREIRA, C. A. L. Entre textos e contextos. Curitiba: Editora CRV, 2016.

QUIJANO, A. Colonialidad del poder y clasificación social. Journal of World-Systems Research, v. 11, n. 2, p. 342-386, 2000.

QUIJANO, A. Colonialidad y modernidad-racionalidad. 2005. Disponivel em: http://pt.scribd.com/ doc/36091067/Anibal-Quijano-Colonialidade-eModernidade-Racionalidade. Acesso em: 20 set. 2016. 
SANTOS, B. de S. Reconhecer para libertar: os caminhos do cosmopolitanismo multicultural. Rio de Janeiro: Civilização Brasileira, 2003.

SILVA, P. B. G. Africanidades. Como valorizar as raízes afro nas propostas pedagógicas. In: MUNANGA K. (org.). Superando o racismo na escola. Brasília, DF: Ministério da Educação, Secretaria de Educação Continuada, Alfabetização e Diversidade, 2005.

STRECK, D. R.; REDIN, E;; ZITKOSKI, J. J. (org.). Dicionário Paulo Freire. Verbete: Inédito Viável (Ana Maria Freire). 2. ed. Belo Horizonte: Autêntica, 2010.

WALSH, C. Interculturalidad, Plurinacionalidad y Decolonialidad: Las Insurgencias Político Epistémicas de Refundar el Estado. Tabula Rasa, Bogotá, n. 9, p. 131-152, jul./dic. 2008.

WALSH, C. ¿̇Son posibles unas ciencias sociales/culturales otras? Reflexiones en torno a las epistemologias decoloniales. Nómadas. Revista Crítica de Ciencias Sociales y Jurídicas, Colômbia, n. 26, p. 102-११, abr. 2007.

Endereços para correspondência: Programa de Pós-Graduação em Educação, Campus Reitor João David Ferreira Lima, s/n, Trindade, Florianópolis, Santa Catarina, Brasil, 88040-900; patti_magalhaes@ hotmail.com 
